\title{
Measuring the availability and geographical accessibility of maternal health services across sub-Saharan Africa
}

\author{
A. S. Wigley ${ }^{1 *}$, N. Tejedor-Garavito ${ }^{1}$, V. Alegana ${ }^{2,1,3}$, A. Carioli', C. W. Ruktanonchai ${ }^{1}$, C. Pezzulo ${ }^{1}$, Z. Matthews ${ }^{4}$, \\ A. J. Tatem ${ }^{1}$ and K. Nilsen ${ }^{1}$
}

\begin{abstract}
Background: With universal health coverage a key component of the 2030 Sustainable Development Goals, targeted monitoring is crucial for reducing inequalities in the provision of services. However, monitoring largely occurs at the national level, masking sub-national variation. Here, we estimate indicators for measuring the availability and geographical accessibility of services, at national and sub-national levels across sub-Saharan Africa, to show how data at varying spatial scales and input data can considerably impact monitoring outcomes.

Methods: Availability was estimated using the World Health Organization guidelines for monitoring emergency obstetric care, defined as the number of hospitals per 500,000 population. Geographical accessibility was estimated using the Lancet Commission on Global Surgery, defined as the proportion of pregnancies within $2 \mathrm{~h}$ of the nearest hospital. These were calculated using geo-located hospital data for sub-Saharan Africa, with their associated travel times, along with small area estimates of population and pregnancies. The results of the availability analysis were then compared to the results of the accessibility analysis, to highlight differences between the availability and geographical accessibility of services.

Results: Despite most countries meeting the targets at the national level, we identified substantial sub-national variation, with $58 \%$ of the countries having at least one administrative unit not meeting the availability target at province level and $95 \%$ at district level. Similarly, 56\% of the countries were found to have at least one province not meeting the accessibility target, increasing to $74 \%$ at the district level. When comparing both availability and accessibility within countries, most countries were found to meet both targets; however sub-nationally, many countries fail to meet one or the other.

Conclusion: While many of the countries met the targets at the national level, we found large within-country variation. Monitoring under the current guidelines, using national averages, can mask these areas of need, with potential consequences for vulnerable women and children. It is imperative therefore that indicators for monitoring the availability and geographical accessibility of health care reflect this need, if targets for universal health coverage are to be met by 2030 .
\end{abstract}

Keywords: Emergency obstetric care, Universal health coverage, Healthcare accessibility, Maternal and newborn health, GIS

\footnotetext{
* Correspondence: a.s.wigley@soton.ac.uk

${ }^{1}$ WorldPop, Geography and Environmental Science, University of

Southampton, Highfield Campus, Southampton SO17 1BJ, UK

Full list of author information is available at the end of the article
}

C The Author(s). 2020 Open Access This article is licensed under a Creative Commons Attribution 4.0 International License, which permits use, sharing, adaptation, distribution and reproduction in any medium or format, as long as you give appropriate credit to the original author(s) and the source, provide a link to the Creative Commons licence, and indicate if changes were made. The images or other third party material in this article are included in the article's Creative Commons licence, unless indicated otherwise in a credit line to the material. If material is not included in the article's Creative Commons licence and your intended use is not permitted by statutory regulation or exceeds the permitted use, you will need to obtain permission directly from the copyright holder. To view a copy of this licence, visit http://creativecommons.org/licenses/by/4.0/ The Creative Commons Public Domain Dedication waiver (http://creativecommons.org/publicdomain/zero/1.0/) applies to the data made available in this article, unless otherwise stated in a credit line to the data. 


\section{Background}

The last few decades have seen substantial global reductions in maternal and neonatal mortality [1], with the maternal mortality ratio (MMR) falling by almost half since the establishment of the Millennium Development Goals [2]. However, despite progress, many countries fell far short of targets, with some seeing little or no change [3]. Of an estimated 295,000 maternal deaths occurring globally in 2017 , approximately $66 \%(196,000)$ of these were in sub-Saharan Africa (SSA) alone, and it is here, where the maternal mortality rate is the highest, that data on births and deaths is often the least robust [4]. Moreover, inequalities in maternal and neonatal health outcomes are not just limited to between countries, but exist within countries as well, presenting fundamental barriers to progress, particularly among the most disadvantaged population groups $[1,5,6]$.

Reducing mortality relies on the provision of high-quality care, and a key emphasis of the 2030 Sustainable Development Goals (SDG) is the achievement of universal health coverage (UHC) [7]. Monitoring progress is key to achieving targets and the World Health Organization (WHO) provide guidelines for estimating the availability and use of emergency obstetric care (EmOC) services [8]. One limitation of these indicators is that they do not consider the geographical accessibility of such services, regarding the time it takes to get to a facility, where the availability of a service may be limited by the number of women who can reach and use it [9]. This limitation is a key contributing factor in positive maternal health outcomes, with the delay in reaching care one of the key determinants in a women's ability to receive the services they need [10]. However, awareness is growing on the need to improve geographical access to emergency care, and a Lancet commission on global surgery defines geographical accessibility as the proportion of the population that can access, within $2 \mathrm{~h}$, a facility with essential surgical and anaesthesia services, with a target of $80 \%$ minimum coverage by 2030 [11].

With an increasing focus on the coverage and accessibility of health services and access to data at increasing spatial resolutions, the use of GIS in maternal health research is growing [12], and several studies identify the need to evaluate the EmOC guidelines [13-15], seen as 'too general and inconsistent' [13]. Douangphachanh et al. [16] consider the use of population density, while Bosomprah et al. [17] suggest the use of births and pregnancies would be a more accurate representation of the needs of a population. This is further explored in Ebener and Stenberg [18] where births are used in place of population to assess geographic accessibility to services, and more recently, in Ebener et al. [19] who propose standardised geographical indicators of physical access to emergency obstetric and newborn care for lowincome and middle-income countries [19].
Further to this, ancillary data, such as travel-time, elevation, roads, and rivers, are considered important when considering the geographical distribution of services [12, $18,20]$, with a variety of spatial modelling techniques employed across a number of studies [21-23]. Methods range from the more simple modelling of Euclidean distances [21] and road network analysis [24], towards a trend of more sophisticated models of accessibility, considering, additionally, the effects of topography, landcover, and means of transportation in the estimation of travel time to the nearest facility $[18,20]$. Ouma et al. [25] model the accessibility of hospitals for women of childbearing age (WoCBA), using a gridded travel-time surface, where each cell represents the cumulative time required to cross pixels in the least cost path. In this, travel-time is modelled across SSA, with the development of the first geocoded inventory of public hospitals with emergency services [26].

Despite guidelines to assess the sub-national coverage of services [27], estimates are often calculated at the national level, which can be misleading [13], and research is limited in the measurement of these indicators at subnational levels, where, at most, only a handful of countries are considered $[18,28]$. This is likely due to a previous lack of spatial data at these smaller administrative levels. Additionally, they do not consider the accessibility of services, regarding the time taken to reach a hospital or the actual population at risk, for example, WoCBA, pregnancies, or births [17-19]. Using high-resolution estimates of population and pregnancies [29-31], hospital locations, and their associated travel times [32], we estimate the availability and geographical accessibility of services across SSA and assess the suitability of these indicators for monitoring maternal health targets. In the context of these estimates, we evaluate how the guidelines for monitoring the availability and use of emergency obstetric care could be revised, to more accurately reflect the target population, accessibility of services, and equitable access to care. As stated in the guidelines [27], we use population to estimate the availability of services, and pregnancies for measuring physical access to emergency obstetric and newborn care in low-income and middle-income countries, as proposed by Ebner et al. [19]. This is carried out at both national and subnational levels to explore how different classifications of coverage [9], varying spatial scales and input data can significantly impact monitoring outcomes.

\section{Methods \\ Data}

Hospital location data, described in a recent study of geographical accessibility to 'emergency hospital care provided by the public sector' across SSA [20], was obtained from the Harvard Dataverse [26]. Compiled from 
various sources, including ministries of health, health management information systems, and government statistical agencies, the data represents hospital services targeted at a broad range of emergency or referral care to the general population [20]. The data includes all hospitals managed by national and local governments, faithbased, and non-governmental organisations, where the facility is the main provider of emergency care and governed by national health guidelines and regulations. Private hospitals and hospitals providing only specialised services are not included in the data, considering the availability of and accessibility to public services only, though this may cause limitations in countries such as the Democratic Republic of the Congo where many rely on access to private health care [33]. Additionally, many hospitals throughout SSA do not provide all signal function functions required to be classified as a CEmOC facility, and information on their CEmOC status is not readily available [29]. It is therefore assumed that hospitals provide the signal functions defined in the guidelines for the provision of comprehensive emergency obstetric care $(\mathrm{CEmOC})$. This data set forms the basis of the analysis and includes forty-eight countries across SSA (Fig. 1a).

Gridded estimates of population and pregnancies were obtained at $1 \mathrm{~km}$ spatial resolution from the WorldPop database for 2015 [34] (Fig. 1b shows the estimated number of pregnancies per $\mathrm{km}^{2}$ across SSA). Detailed methods are described elsewhere [29-31], though to summarise briefly, population estimates are first derived using the most recently available data at the lowest available administration unit, using a semi-automated dasymetric modelling approach, then disaggregated further by age and sex, to determine numbers of WoCBA. Country respective fertility rates are then applied, using the most recently available data on stillbirths, miscarriages, and abortions, to estimate the numbers of pregnancies per $1 \mathrm{~km}$ grid cell. It is important to note, that while the population estimates can be determined to a relatively good degree of accuracy, information on subnational birth rates are much less widely available, and sub-national estimates of pregnancies, abortions, and stillbirths do not currently exist. The method therefore relies on the input of national estimates to determine these rates and an assumption of no within-country variation [35].

Geographical accessibility was estimated by considering the travel time to the nearest hospital, using a gridded travel-time surface [32], where each cell represents the cumulative time required to cross pixels in the least cost path. This surface was generated using AccessMod5 [36], a WHO tool used for modelling geographical accessibility to health care. Detailed methods are described elsewhere [37], though, in summary, the surface is created by modelling the effects of topography, available transport networks, land-cover and barriers to travel, using cost-distance analysis, with a composite of walking and motorised travel speeds and the set of geo-located hospitals [26]. This model assumes motorised travel along the road
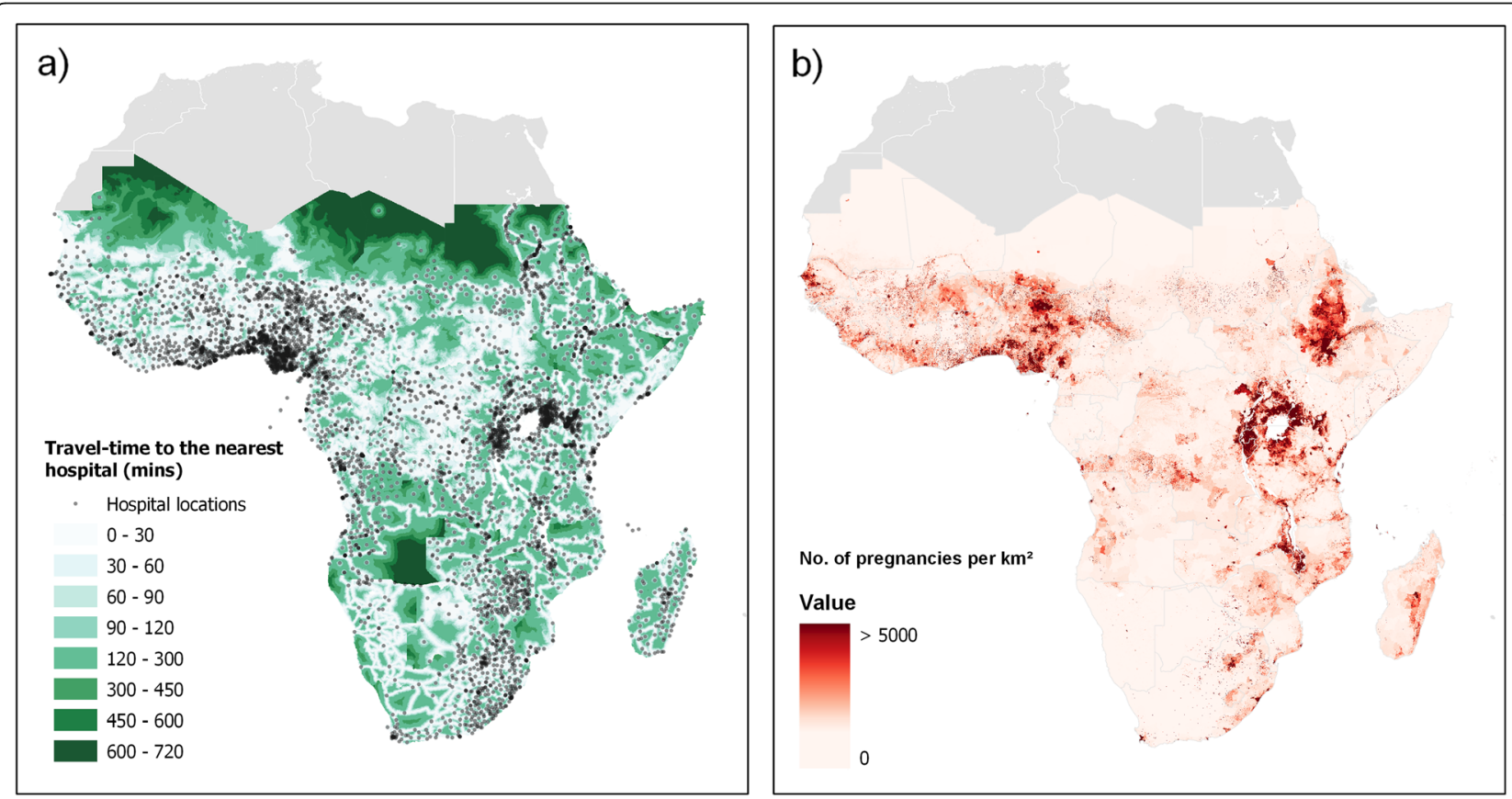

Fig. 1 Map a showing travel-time to the nearest hospital and map $\mathbf{b}$ showing the estimated number of pregnancies in 2015 per $\mathrm{km}^{2}$ 
network, assigning $80 \mathrm{~km} / \mathrm{h}$ on primary roads, $60 \mathrm{~km} /$ $\mathrm{h}$ on secondary roads, and $10 \mathrm{~km} / \mathrm{h}$ on tertiary roads, with all other non-road cells assigned a speed of up to $5 \mathrm{~km} / \mathrm{h}$, depending on the land-cover type and slope, and assuming patients could walk, were carried, or transported by other means [38]. However, where access to motorised travel is not available, and where seasonal variations can impact road conditions, this model may largely overestimate the time taken to reach the nearest hospital $[39,40]$. The model is also confined to national borders, assuming patients do not cross the border to reach the nearest hospital, though not constrained by sub-national zoning. Figure 1b) shows both the gridded travel-time data and hospital locations.

The Global ADMinistrative areas (GADM) database [41] was used to define administrative units at both national and sub-national levels. As terminology varies across countries, different administrative levels are referred to using standardised abbreviations. National boundaries are referred to using the country name or ISO code [42] and sub-national boundaries using adm-1 or adm-2, where adm-1 typically represents the state or province level and adm-2 the district or county level. Where sub-national boundaries were not available, the country was not analysed at these levels. The gridded travel-time surface was used to select the countries to use for the analysis, with 45 countries analysed at the national and adm-1 levels and 43 at adm-2, where adm2 level boundaries for Cape Verde and Lesotho were not available.

\section{Analysis}

The availability of services was defined as the number of hospitals per 500,000 population, with a minimum target of one comprehensive facility for every 500,000 population. This was carried out at both national and subnational levels, assuming hospitals provide the comprehensive care set out in the guidelines [8]. Estimates were calculated by multiplying the number of hospitals within a defined administrative unit, by 500,000, and zonal statistics used to determine the population and hospital counts for each unit. Where the number of hospitals per 500,000 population is greater than one, the minimum level of care is assumed to have been met. Following previous work [43], the percentage of the target achieved was subsequently calculated, to provide a measure of achievement at both national and sub-national levels. A combination of ArcGIS 10.4.2 [44], Python 2.7.10, and R version 3.5.0 [45] was used in the analysis.

Geographical accessibility was defined as at least $80 \%$ of pregnancies within an administrative unit located within $2 \mathrm{~h}$ to the nearest hospital [11, 19]. For this indicator, pregnancies were estimated instead of the general population $[17,19]$, to be more reflective of the population at risk. Using the gridded travel-time surface and the WorldPop pregnancies data sets, the indicator was calculated at both national and sub-national administration levels. Using the Arcpy Python package, the travel surface was reclassified into time zones, whereby all cells within a zone were classified by the value 1 , and all others as 0 , and each zone multiplied by the pregnancy data sets, to calculate the pregnancy counts for each of the time zones. Zonal statistics were used to calculate the numbers of pregnancies for each administrative unit, and outputs combined and reformatted using a combination of Python and R. From the resulting counts, their associated proportions were calculated, and the critical 2-h maximum travel time $[8,46]$ used to group the outputs into those 'within 2-h travel time' and those 'greater than 2-h travel time' from the nearest hospital, and the $80 \%$ minimum coverage target [11] used to define a boolean style classification. The outputs were joined to their associated administrative boundaries using ArcGIS.

With both indicators, it is important to note that their calculation relies on the use of defined administrative boundaries. This is limited in that it cannot account for the utilisation of cross border facilities and is highly sensitive in the partitioning of the administrative units. This is known as the Modifiable Areal Unit Problem (MAUP), which describes how spatial summary measures are inherently influenced by the administrative boundaries that they are reported at [47].

The results of the geographical accessibility analysis were then compared to those of the availability analysis to highlight those areas meeting the availability targets but not meeting the geographical accessibility targets, regarding the 2 -h travel time $[8,46]$ and the $80 \%$ coverage threshold [11]. These were plotted and four classifications identified: (1) those not meeting the availability or geographical accessibility thresholds, (2) those meeting the availability threshold but not the geographical accessibility threshold, (3) those meeting the geographical accessibility threshold but not the availability threshold, and (4) those meeting both the availability and geographical accessibility thresholds. To facilitate comparability between countries of varying size and administrative units, the average spatial resolution (ASR) was calculated, as the square root of the country area $\left(\mathrm{km}^{2}\right)$ divided by the total number of administration units, for each country at adm-1 and adm-2, classifying the countries into quartiles based on the minimum and maximum ASR values at both sub-national levels.

\section{Results}

Indicators measuring the availability and geographical accessibility of hospitals were estimated at national and sub-national levels. The geographical distribution of 
these indicators is shown in Fig. 2, to highlight areas where targets have not been met.

We estimated the availability of hospitals for 45 countries at the national and adm- 1 administrative levels, and for 43 at adm-2 (Additional file 1). At the national level, all countries were found to meet the availability target (1 hospital per 500,000 population), with the exception of Ethiopia (77\% of target) and Senegal (96\% of target) (Fig. 2ai and Additional file 2). However, we identified substantial subnational variability, with $26 / 45$ (58\%) of the countries at adm-1 (Additional file 3) and 41/43 countries (95\%) at adm-2 (Additional file 4) found to have at least one administrative unit not meeting this target. This variation at the subnational level can be visualised in Fig. 3, which plots the availability estimates at adm-1, where each dot represents a single administrative unit, considering the population size and the number of hospitals available. This figure highlights the variability in the availability of services both between and within countries. For example, many of the administrative units with larger population sizes exceed the target of 1 hospital per 500,000 population, irrespective of country. However, in some countries, there are some administrative units with very large population sizes not meeting the target (i.e. the Oromia and Amhara regions of Ethiopia) (Fig. 3). In contrast to this, there are other countries with far less populous administrative units, exceeding the target by up to 11 times.

We estimated the geographical accessibility of hospitals for 45 countries for national and adm-1 levels and 43 at adm-2. At the national level, all countries were found to meet the geographical accessibility target $(80 \%$ of all pregnancies located within 2-h travel time of the nearest hospital), with the exception of Eritrea (71\%) (Additional file 5). Again, at sub-national administration levels, we identified substantial variability, with $56 \%$ of the countries at adm- 1 and $74 \%$ at adm-2 having at least one administration unit not meeting the target. With increasing administrative units, a clear geographical pattern emerges, where areas in the north and north-east as well as central SSA are identified to have increasing areas at sub-national levels, not meeting the target (Fig. 2). National-level summary statistics can be visualised in Fig. 4, showing the median, upper, and lower quartiles,

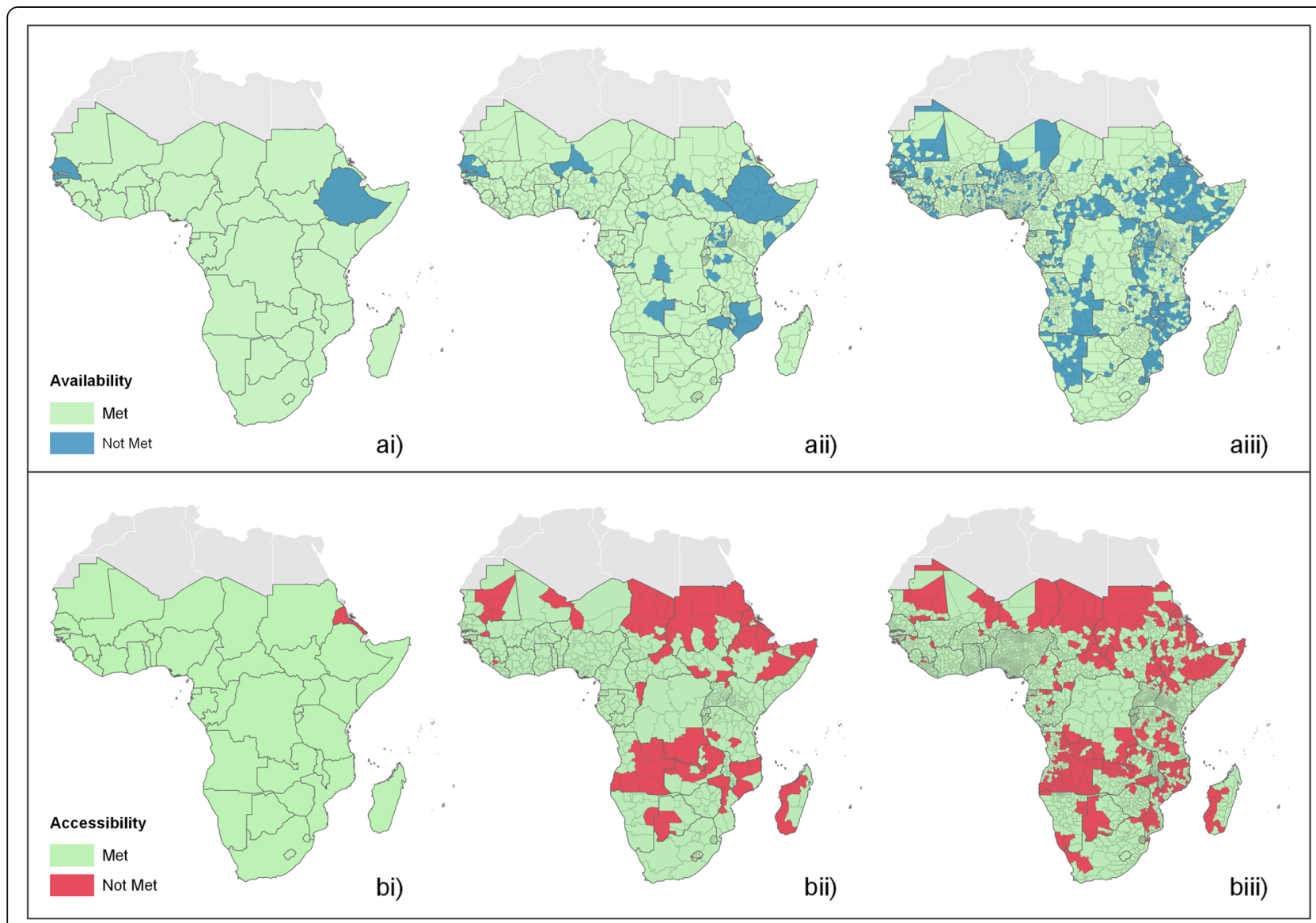

Fig. 2 Maps showing where the availability target has not been met, at ai national, aii adm-1, and aiii adm-2 levels, and where the accessibility target has not been met at bi national, bii adm-1, and biii adm-2 levels 


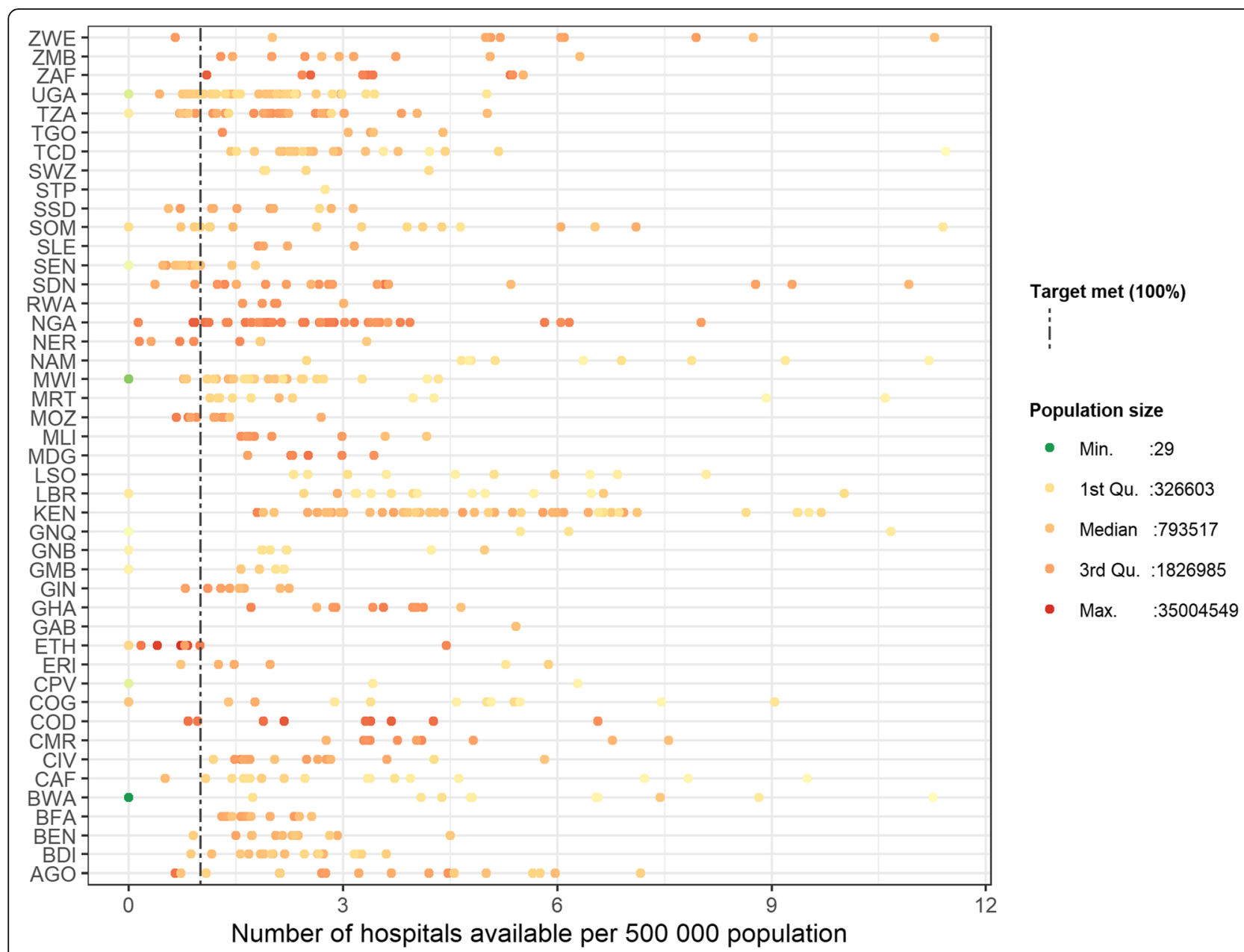

Fig. 3 The number of hospitals available per 500,000 population, by country, for each adm-1 unit, classified by population size (with breaks at the minimum, 1st quartile, mean, 3rd quartile, and maximum values)

and outlying data values, of the proportion of pregnancies within 2-h of the nearest hospital at adm-2. At this level, although many of the units meet the target, large geographical variations can be observed, where, for example, in Angola, Mozambique and Mauritania, more than half of the units at adm-2 do not meet the target, and only 11 countries out of 43 have all their admin units above the $80 \%$ threshold.

To examine how the estimates of availability and geographical accessibility vary geographically, the results from the availability analysis were compared with the results from the geographical accessibility analysis. At the national level, 42 (93\%) of the countries were found to meet both targets, with just one country identified as meeting the availability but not the geographical accessibility target, and two countries as meeting the geographical accessibility but not the availability target (Additional file 6). At adm-1, 12 countries (27\%) were identified to have units not meeting both targets, 18 countries $(40 \%)$ to have units meeting the availability but not the geographical accessibility target, and 34 countries $(76 \%)$ to have units meeting the geographical accessibility but not the availability target (Additional file 7). Then at adm-2, 23 countries (53\%) were identified to have units not meeting both targets, with 26 countries (60\%) to have units meeting the availability but not the geographical accessibility target, and 40 countries (93\%) to have units meeting the geographical accessibility but not the availability target (Additional file 8).

\section{Discussion}

With increasingly available and reliable spatial data at finer resolutions [48], the geographical coverage of health care services can now be monitored with increasing accuracy, a key consideration towards the achievement of UHC [49]. Using recently compiled hospital location data for 45 countries across SSA [26], and high-resolution gridded population and pregnancy count estimates [50], we explore for the 


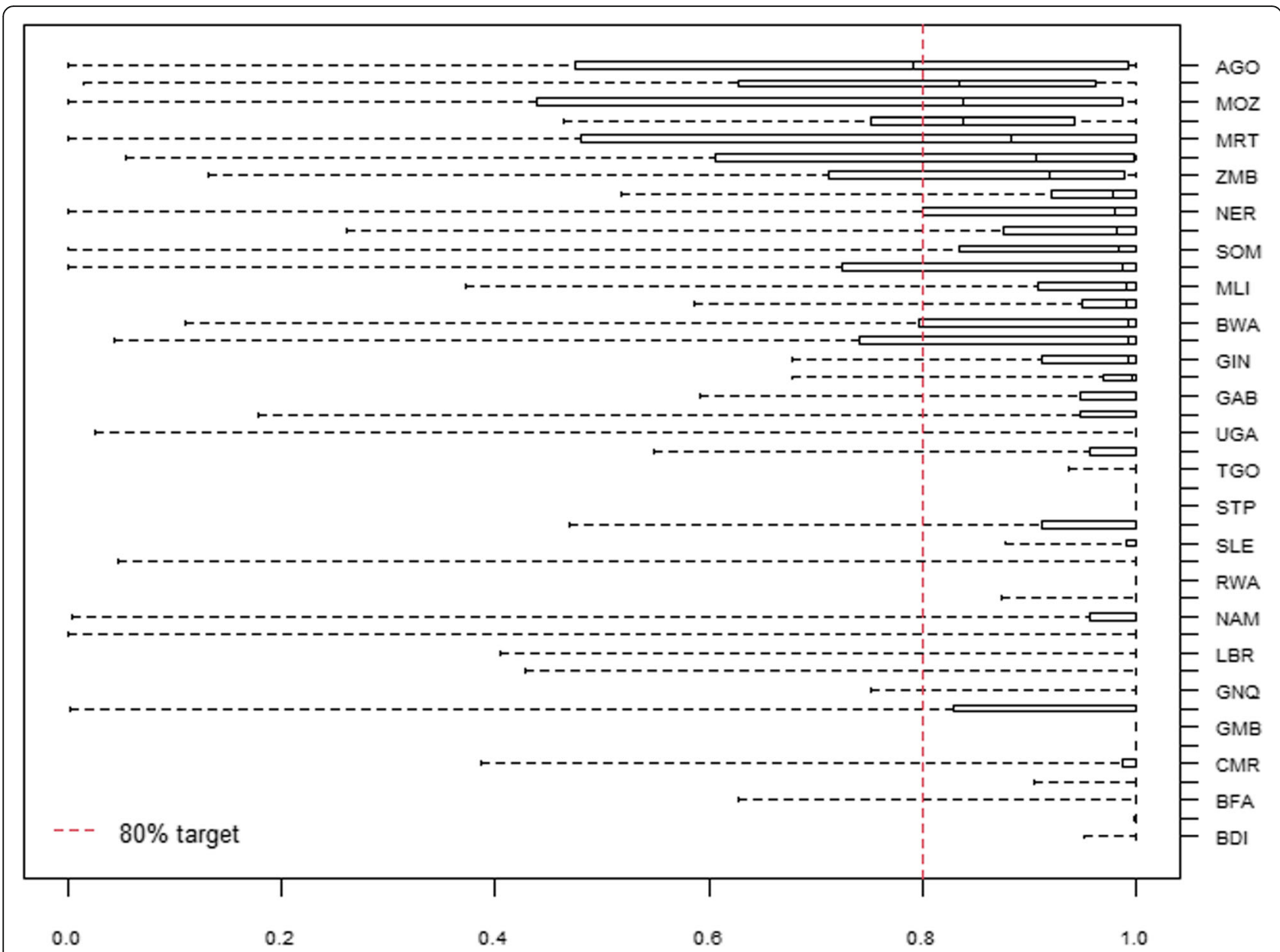

Fig. $4 \mathrm{~A}$ box plot showing the variation in the median, upper and lower quartiles, and outlying data values of the proportion of pregnancies within 2-h travel time of the nearest hospital, ordered by median value (adm-2 level)

first time how analysis at varying spatial scales can uncover areas of need previously undetected. While considering the results, it is important to note that we use population to estimate the availability of services, as stated by the guidelines [27], and pregnancies for measuring physical access to emergency obstetric and newborn care in low-income and middleincome countries, as proposed by Ebner et al. [19]. Our results estimate that across SSA, there is an average availability of two hospitals per 500,000 people, with $93 \%$ of pregnancies occurring within $2 \mathrm{~h}$ of the nearest hospital, and at the national level, the results again indicate adequate coverage, with just a few countries not meeting the targets. However, when calculated at sub-national levels, in Angola and Malawi for example, it is clear that there are increasing areas of need not meeting the target, $11 \%$ and $18 \%$ at adm-1, and $32 \%$ and $82 \%$ at the adm-2, respectively, showing how the national averages usually reported for monitoring purposes can mask significant variation.
These findings highlight the importance of monitoring at sub-national levels, and while indicators exist for subnational evaluation [8], clearer guidance on how to calculate these is needed. For example, it is not specified whether to consider a minimum population size when calculating the geographical distribution of hospitals at subnational levels, an important consideration in the assessment of health system coverage, where the monitoring of smaller administrative areas will naturally concern lower populations. Additionally, the suitability of using population as recommended in the guidelines [8], rather than women of childbearing age, births or pregnancies [17], is considered misleading [14] as it cannot accurately reflect the population at risk. This may arguably under-estimate health system coverage; however, it does not account for variations in the spatial demographics of women of childbearing age, for which the availability of emergency obstetric care is most needed. Furthermore, the guidelines do not include an explicit measure of accessibility; rather, accessibility is measured implicitly in 
the calculation of the availability of services at subnational levels, and cannot truly reflect the time taken for women to them.

To further consider the accessibility of services, we measure the travel time taken to reach the nearest hospital, as recommended by global guidelines [11]. However, the definition of geographical accessibility as used in this paper [11], may likely overestimate coverage, due to the assumptions made in the estimation of travel time. For example, the geographical accessibility surface assumes fixed travel speeds (maximum speed) for specific road and land cover types $[37,51]$. However, this is not a true reflection of the ground situation, where road conditions can vary considerably between and within countries, as well as according to the season, often resulting in a reduction in speed where road conditions are poor $[28,52]$. The geographical accessibility surface additionally assumes that people travelling on primary, secondary, and tertiary roads have access to motorised transport that travel at the assumed speeds; however, for many, access to motorised transport is limited [37].

Furthermore, the 2-h travel time recommended by the indicator has been critiqued as a benchmark for geographical accessibility, and literature references a "golden hour" where access to emergency obstetric care within the first hour can dramatically decrease adverse outcomes and improve chances of survival for women and their children [53]. Reducing the 2-h benchmark to consider this "golden hour" would have shown a reduction in service coverage, resulting in an increase in the number of areas not meeting this target and number of women at risk. Furthermore, using a minimum threshold of at least $80 \%$ population coverage within this 2 -h travel time is problematic, where in the context of the SDG "leave no one behind" agenda, it implies that it is acceptable that a fifth of population at risk do not have access to critical services. It is additionally important to note that any measure of geographical accessibility does not consider barriers related to the availability, affordability, acceptability, and appropriateness of services; factors which have shown to contribute substantially to delays in receiving care [54-56], even when geographical accessibility might otherwise be considered adequate.

We additionally assume, as in Ouma et al. [20], when measuring geographical accessibility, that hospitals provide CEmOC. This is stressed as a key limitation to the study since previous research has found that health facilities in SSA do not always provide the required number of signal functions to be classified as CEmOC [28]. As a result, it is likely that we overestimate both the availability and accessibility of services. However, as it is the most complete and up to date record of public hospitals in SSA, it provides a considerable opportunity to evaluate the availability and geographical accessibility of hospitals at a scale not achieved before, and thus, providing valuable insight into the performance of these indicators at sub-national levels. Future work should therefore evaluate the services provided by each facility, to assess whether the use of hospitals, as defined in this analysis, can accurately reflect the key signal functions outlined in the guidelines for monitoring EmOC [8]. Further analysis should additionally consider the use of more comprehensive facility datasets, including health facilities, private hospitals, and hospitals providing only specialised services [57].

\section{Conclusions}

In exploring how the analysis of data at increasing spatial resolutions can indeed uncover areas of need overlooked, we demonstrate how the use of different input data, methods of analysis, and most pertinently, how the construction of the indicators themselves, can considerably impact monitoring outcomes. Given these caveats, the definitions of both the availability and geographical accessibility indicators should be reviewed, harmonised and standardised, to effectively measure progress towards the SDG within the context of UHC.

\section{Supplementary information}

Supplementary information accompanies this paper at https://doi.org/10. 1186/s12916-020-01707-6.

Additional file 1: Table 1. A descriptive table of the countries studied, their total area, total population, and total number of adm1 and adm2 units.

Additional file 2: Table 2. Shows the availability of hospitals at the national level (number of hospitals per 500000 population), and the corresponding percentage of the target achieved.

Additional file 3: Table 3. Shows the proportion of regions not meeting the availability target at adm-1, along with their associated ASR grouping to signify comparability between countries.

Additional file 4: Table 4. Shows the proportion of regions not meeting the availability target at adm-2, along with their associated ASR grouping to signify comparability between countries.

Additional file 5: Table 5. Shows the total number of pregnancies, number of pregnancies within 2 -h of the nearest hospital, and relative proportion of pregnancies within $2-h$ of the nearest hospital, at the national level.

Additional file 6: FigureS1. Compares the availability and accessibility indicator estimates at the national level.

Additional file 7: Table 6. Compares the number of countries and regions meeting each of the classifications at adm-1.

Additional file 8: Table 7. Compares the number of countries and regions meeting each of the classifications at adm- 2 .

Abbreviations

ASR: Average spatial resolution; CEmOC: Comprehensive emergency obstetric care; EmOC: Emergency obstetric care; GADM: Global

ADMinistrative areas; MMR: Maternal mortality ratio; SDG: Sustainable Development Goals; SSA: Sub-Saharan Africa; UHC: Universal health coverage; WHO: World Health Organization; WoCBA: Women of childbearing age 


\section{Acknowledgements}

We would like to acknowledge the Wellcome Trust and the UK Department for International Development (DFID) for funding the project and making it possible. We would also like to acknowledge William H. James for his contribution to the initial preparation of datasets used in the analysis.

\section{Authors' contributions}

AW conducted the analysis and wrote the first draft of the manuscript with the assistance and leadership of NTG, KN, and AJT. NTG contributed to study design, data collection, analysis, interpretation, and writing. KN and AJT contributed to study design, data interpretation, and writing. AC and CP contributed to data analysis and interpretation. VA, ZM, and CWR contributed to data interpretation and writing. All authors contributed to editing and revising the manuscript and approved its final version.

\section{Funding}

This work was principally funded by the Wellcome Trust and UK Department for International Development (DFID) (grant number: 204613/Z/16/Z).

\section{Availability of data and materials}

The datasets analysed during the current study are available from the following repositories:

- Sub-Saharan Public Hospitals Geo-coded database, https://dataverse.harvard.edu/dataset.xhtml?persistentld=doi:10.7910/DVN/JTL9VY [20]. -Worldpop Pregnancy distributions, https://www.worldpop.org/project/ categories?id=6 [34]

- GADM Administrative boundaries, https://gadm.org/data.html [41]. - Travel-time raster, https://figshare.com/articles/National_and_subnational_ variation_in_pattern_of_febrile_case_management_in_sub-Saharan_Africa/ 7160363 [32].

\section{Ethics approval and consent to participate}

Not applicable

\section{Consent for publication}

Not applicable

\section{Competing interests}

We declare no competing interests.

\section{Author details}

'WorldPop, Geography and Environmental Science, University of Southampton, Highfield Campus, Southampton SO17 1BJ, UK. ${ }^{2}$ Population Health Unit, Kenya Medical Research Institute - Wellcome Trust Research Programme, P.O. Box 43640, Nairobi 00100, Kenya. ${ }^{3}$ Faculty of Science and Technology, Lancaster University, Lancaster LA1 4YR, UK. ${ }^{4}$ Division of Social Statistics and Demography \& Centre for Global Health, Population, Poverty and Policy, Faculty of Social and Human Sciences, University of Southampton, Southampton SO17 1BJ, UK.

\section{Received: 28 February 2020 Accepted: 13 July 2020}

\section{Published online: 08 September 2020}

\section{References}

1. Arts M, Begin F, Chaiban T, Chandy L, Hayashi C, Hereward M, et al. Every child alive. 2018. https://data.unicef.org/wp-content/uploads/2018/02/EveryChild-Alive-report_FINAL-1.pdf. Accessed 27 Sept 2018.

2. Koblinsky M, Moyer CA, Calvert C, Campbell J, Campbell OMR, Feigl AB, et al. Quality maternity care for every woman, everywhere: a call to action. Lancet. 2016;388:2307-20. https://doi.org/10.1016/S0140-6736(16)31333-2.

3. Graham W, Woodd S, Byass P, Filippi V, Gon G, Virgo S, et al. Diversity and divergence: the dynamic burden of poor maternal health. Lancet. 2016;388: 2164-75. https://doi.org/10.1016/S0140-6736(16)31533-1.

4. WHO. Trends in maternal mortality 2000 to 2017: estimates by WHO, UNICEF, UNFPA, World Bank Group and the United Nations Population Division. 2019. https://apps.who.int/iris/handle/10665/327596. Accessed 5 Jun 2020.

5. WHO WB. Tracking Universal Health Coverage: 2017 Global Monitoring Report: executive summary. 2017

6. Singh A. Supply-side barriers to maternal health care utilization at health sub-centers in India. PeerJ. 2016. https://doi.org/10.7717/peerj.2675.
7. Evans DB, Hsu J, Boerma T. Universal health coverage and universal access Bull World Health Organ. 2013; https://www.who.int/bulletin/volumes/91/ 8/13-125450.pdf. Accessed 29 May 2018.

8. World Health Organisation. Monitoring emergency obstetric care, a handbook. 2009. http://www.unfpa.org/sites/default/files/pub-pdf/obstetric_ monitoring.pdf. Accessed 29 Nov 2017.

9. Tanahashi T. Health service coverage and its evaluation. Bull World Health Organ. 1978;56:295-303 https:/pubmed.ncbi.nlm.nih.gov/96953/. Accessed 15 Jan 2019.

10. Gabrysch S, Campbell OM. Still too far to walk: literature review of the determinants of delivery service use. BMC Pregnancy Childbirth. 2009. https://doi.org/10.1186/1471-2393-9-34

11. Meara JG, Leather AJM, Hagander L, Alkire BC, Alonso N, Ameh EA, et al. Global Surgery 2030: evidence and solutions for achieving health, welfare, and economic development. Lancet. 2015;386:569-624. https://doi.org/10. 1016/S0140-6736(15)60160-X

12. Makanga PT, Schuurman N, Von Dadelszen P, Firoz T. A scoping review of geographic information systems in maternal health. Int J Gynecol Obstet. 2016. https://doi.org/10.1016/j.ijgo.2015.11.022.

13. Collender G, Gabrysch S, Campbell OMR. Reducing maternal mortality: better monitoring, indicators and benchmarks needed to improve emergency obstetric care. Trop Med Int Health. 2012. https://doi.org/10. 1111/j.1365-3156.2012.02983.x.

14. Banke-Thomas A, Wright K, Sonoiki O, Banke-Thomas O, Babatunde Ajayi OI, $\mathrm{OA}$, To. Assessing emergency obstetric care provision in low and middleincome countries: a systematic review of the application of global guidelines. Glob Health Action. 2016. https://doi.org/10.3402/gha.v9.31880.

15. Paxton A, Bailey P, Lobis S. The United Nations Process Indicators for emergency obstetric care: reflections based on a decade of experience. Int J Gynecol Obstet. 2006;95:192-208. https://doi.org/10.1016/j.ijgo.2006.08.009.

16. Douangphachanh X, Ali M, Outavong P, Alongkon P, Sing M, Chushi K. Availability and use of emergency obstetric care services in public hospitals in Laos PDR: a systems analysis. Biosci Trends. 2010:4:318-24 www. biosciencetrends.com. Accessed 25 Feb 2020.

17. Bosomprah S, Tatem AJ, Dotse-Gborgbortsi W, Aboagye P, Matthews Z. Spatial distribution of emergency obstetric and newborn care services in Ghana: using the evidence to plan interventions. Int J Gynecol Obstet. 2016. https://doi.org/10.1016/j.ijgo.2015.11.004.

18. Ebener S, Stenberg K. Investing the marginal Dollar for maternal and newborn health: geographic accessibility analysis for emergency obstetric care services in Lao People's Democratic Republic. 2016. http://www.who. int/about/licensing/copyright_form/index.html. Accessed 23 Mar 2018

19. Ebener S, Stenberg K, Brun M, Monet JP, Ray N, Sobel HL, et al. Proposing standardised geographical indicators of physical access to emergency obstetric and newborn care in low-income and middle-income countries. BMJ Glob Health. 2019;4:1-11. https://doi.org/10.1136/bmjgh-2018-000778.

20. Ouma PO, Maina J, Thuranira PN, Macharia PM, Alegana VA, English M, et al. Access to emergency hospital care provided by the public sector in subSaharan Africa in 2015: a geocoded inventory and spatial analysis. Lancet Glob Health. 2018. https://doi.org/10.1016/S2214-109X(17)30488-6.

21. Gabrysch S, Cousens S, Cox J, Campbell OMR. The influence of distance and level of care on delivery place in rural Zambia: a study of linked national data in a geographic information system. PLoS Med. 2011;8:e1000394. https://doi.org/10.1371/journal.pmed.1000394.

22. Ruktanonchai CW, Ruktanonchai NW, Nove A, Lopes S, Pezzulo C, Bosco C, et al. Equality in maternal and newborn health: modelling geographic disparities in utilisation of care in five East African countries. PLoS One. 2016;11:e0162006. https://doi.org/10.1371/journal.pone.0162006.

23. Comber AJ, Brunsdon C, Radburn R. A spatial analysis of variations in health access: linking geography, socio-economic status and access perceptions; 2011. https://doi.org/10.1186/1476-072X-10-44.

24. Joharifard S, Rulisa S, Niyonkuru F, Weinhold A, Sayinzoga F, Wilkinson J, et al. Prevalence and predictors of giving birth in health facilities in Bugesera District, Rwanda. BMC Public Health. 2012;12:1. https://doi.org/10. 1186/1471-2458-12-1049.

25. Ouma PO, Maina J, Thuranira PN, Macharia PM, Alegana VA, English M, et al Access to emergency hospital care provided by the public sector in subSaharan Africa in 2015: a geocoded inventory and spatial analysis. Lancet Glob Health. 2018:6:e342-50. https://doi.org/10.1016/S2214-109X(17)30488-6.

26. Ouma PO, Okiro EA, Snow RW. Sub-Saharan public hospitals geo-coded database - population health dataverse. 2017. https://dataverse.harvard.edu/ dataset.xhtml?persistentld=doi:10.7910/DVN/JTL9VY. Accessed 27 Sept 2018. 
27. WHO. Monitoring emergency obstetric care, a handbook. 2009. http://www. unfpa.org/sites/default/files/pub-pdf/obstetric_monitoring.pdf. Accessed 29 Nov 2017.

28. Banke-Thomas A, Wright K, Collins L, Health Pol M, Mgt P. Assessing geographical distribution and accessibility of emergency obstetric care in sub-Saharan Africa: a systematic review. 2018. https://doi.org/10.7189/jogh. 09.010414.

29. Tatem AJ, Campbell J, Guerra-Arias M, De Bernis L, Moran A, Matthews Z. Mapping for maternal and newborn health: the distributions of women of childbearing age, pregnancies and births. Int J Health Geogr. 2014; https:// www.ncbi.n/m.nih.gov/pmc/articles/PMC3923551/pdf/1476-072X-13-2.pdf. Accessed 5 Feb 2018.

30. Stevens FR, Gaughan AE, Linard C, Tatem AJ. Disaggregating census data for population mapping using random forests with remotely-sensed and ancillary data. PLoS One. 2015. https://doi.org/10.1371/journal.pone.0107042.

31. James WHM, Tejedor-Garavito N, Hanspal SE, Campbell-Sutton A, Hornby GM, Pezzulo C, et al. Gridded birth and pregnancy datasets for Africa, Latin America and the Caribbean. Nat Publ Gr. 2018. https://doi.org/10.1038/ sdata.2018.90.

32. Alegana VA. National and subnational variation in pattern of febrile case management in sub-Saharan Africa. Figshare. 2018; https://figshare.com/ articles/National_and_subnational_variation_in_pattern_of_febrile_case_ management_in_sub-Saharan_Africa/7160363. Accessed 25 Feb 2020.

33. Brunner B, Combet V, Callahan S, Holtz J, Mangone E, Barnes J, et al. The role of the private sector in improving the performance of the health system in the Democratic Republic of Congo. 2019. http://documents. worldbank.org/curated/en/335191548260500149/The-Role-of-the-PrivateSector-in-Improving-the-Performance-of-the-Health-System-in-theDemocratic-Republic-of-Congo. Accessed 9 Jun 2020.

34. Worldpop. WorldPop :.: Pregnancies. 2020. https://www.worldpop.org/ project/categories?id=6. Accessed 25 Feb 2020.

35. Singh S, Darroch JEAL. Adding it up: the need for and cost of maternal and new- born care-estimates for 2012, vol. 2012. New York: Guttmacher Institute; 2013. https://www.guttmacher.org/report/adding-it-up-meetingcontraceptive-mnh-needs-pakistan. Accessed 4 Jun 2019.

36. WHO. AccessMod 5 | Supporting Universal Health Coverage by modelling physical accessibility to health care; 2017. https://doi.org/10.1186/1476072X-7-63.

37. Alegana VA, Maina J, Ouma PO, Macharia PM, Wright J, Atkinson PM, et al. National and sub-national variation in patterns of febrile case management in sub-Saharan Africa. Nat Commun. 2018. https://doi.org/10.1038/s41467018-07536-9.

38. Alegana VA, Wright JA, Pentrina U, Noor AM, Snow RW, Atkinson PM. Spatial modelling of healthcare utilisation for treatment of fever in Namibia. 2012. https://doi.org/10.1186/1476-072X-11-6.

39. Tatenda Makanga P, Schuurman N, Sacoor C, Edith Boene H, Vilanculo F, Vidler $\mathrm{M}$, et al. Seasonal variation in geographical access to maternal health services in regions of southern Mozambique. Int J Health Geogr. 2017;16:1. https://doi.org/10.1186/s12942-016-0074-4

40. Kyei-Nimakoh M, Carolan-Olah M, McCann TV. Access barriers to obstetric care at health facilities in sub-Saharan Africa-a systematic review. Syst Rev. 2017;6:1-16. https://doi.org/10.1186/s13643-017-0503-x.

41. University of California. Global Administrative Areas v2.8. 2015. http://gadm. org/. Accessed 16 Mar 2018.

42. One World Nations Online. Country codes list. 2018. https://www. nationsonline.org/oneworld/country_code_list.htm. Accessed 27 Sept 2018.

43. Gething PW, Johnson FA, Frempong-Ainguah F, Nyarko P, Baschieri A, Aboagye $P$, et al. Geographical access to care at birth in Ghana: a barrier to safe motherhood. BMC Public Health. 2012. https://doi.org/10.1186/14712458-12-991.

44. Environmental Systems Research Institute. ArcMap | ArcGIS Desktop. 2019. https://desktop.arcgis.com/en/arcmap/. Accessed 8 Jan 2020.

45. The R Foundation. R: The R Project for Statistical Computing 2020. https:// www.r-project.org/. Accessed 25 Feb 2020.

46. Kwast BE. Postpartum haemorrhage: its contribution to maternal mortality. Midwifery. 1991. https://doi.org/10.1016/S0266-6138(05)80229-3.

47. Fotheringham AS, Wong DWS. The modifiable areal unit problem in multivariate statistical analysis. Environ Plan A. 1991;23:1025-44. https://doi. org/10.1068/a231025.

48. Tatem AJ. Comment: WorldPop, open data for spatial demography; 2017. https://doi.org/10.1038/sdata.2017.4.
49. Hogan DR, Stevens DSc GA, Hosseinpoor AR, Hogan DR, Stevens GA, Reza Hosseinpoor A, et al. Monitoring universal health coverage within the Sustainable Development Goals: development and baseline data for an index of essential health services. Lancet Glob Health. 2018. https://doi.org/ 10.1016/S2214-109X(17)30472-2.

50. Worldpop. How would you like to access our data? http://www.worldpop. org.uk/data/get_data/. Accessed 27 Sept 2018.

51. Ray N, Ebener S. AccessMod 3.0: computing geographic coverage and accessibility to health care services using anisotropic movement of patients. Int J Health Geogr. 2008. https://doi.org/10.1186/1476-072X-7-63.

52. Hirose A, Borchert M, Cox J, Shah Alkozai A, Filippi V. Determinants of delays in travelling to an emergency obstetric care facility in Herat, Afghanistan: an analysis of cross-sectional survey data and spatial modelling. 2015. https:// doi.org/10.1186/s12884-015-0435-1.

53. Anto-Ocrah M, Cushman J, Sanders M, De T, Dye V. A woman's worth: an access framework for integrating emergency medicine with maternal health to reduce the burden of maternal mortality in sub-Saharan Africa. 2020. https://doi.org/10.1186/s12873-020-0300-z.

54. Penchansky R, Thomas J. The concept of access. 1981. https://journals.lww. com/Iww-medicalcare/Abstract/1981/02000/The_Concept_of_Access_ Definition_and_Relationship.1.aspx\#pdf-link. Accessed 16 Feb 2019.

55. Guagliardo MF. Spatial accessibility of primary care: concepts, methods and challenges. Int J Health Geogr. 2004; http://www.ij-healthgeographics.com/ content/3/1/3. Accessed 10 Apr 2019.

56. Anto-Ocrah M, Cushman J, Sanders M, De T, Dye V. A woman's worth: an access framework for integrating emergency medicine with maternal health to reduce the burden of maternal mortality in sub-Saharan Africa. https:// doi.org/10.1186/s12873-020-0300-z.

57. Maina J, Ouma PO, Macharia PM, Alegana VA, Mitto B, Fall IS. et al, A spatial database of health facilities managed by the public health sector in sub Saharan Africa background and summary. https://doi.org/10.1038/s41597019-0142-2.

\section{Publisher's Note}

Springer Nature remains neutral with regard to jurisdictional claims in published maps and institutional affiliations.

\section{Ready to submit your research? Choose BMC and benefit from:}

- fast, convenient online submission

- thorough peer review by experienced researchers in your field

- rapid publication on acceptance

- support for research data, including large and complex data types

- gold Open Access which fosters wider collaboration and increased citations

- maximum visibility for your research: over $100 \mathrm{M}$ website views per year

At $\mathrm{BMC}$, research is always in progress.

Learn more biomedcentral.com/submissions 